\title{
ELECTRICAL-THERMAL COUPLING OF INDUCTION MACHINE FOR IMPROVED THERMAL PERFORMANCE
}

\author{
N. V. Irokwe ${ }^{1, *}$ and O. I. Okoro ${ }^{2}$

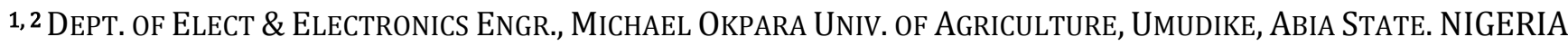 \\ E-mail addresses:1 irons.ndu@gmail.com,2oiokoro@yahoo.co.uk
}

\begin{abstract}
This paper summarizes the electrical-thermal coupling of induction machine for improved thermal performance. The interaction of its electrical and mechanical parts leads to an increase in temperature which if not properly monitored may lead to breakdown of the machine. The paper therefore, set out to study the effect of electrical and thermal model on the machine. A two-mass system is used to model the mechanical part of the machine. A lumped parameter method was used in the thermal model of the machine. The system of non-linear ordinary differential equations which describe the thermal behaviour of the machine in transient state were solved numerically using the fourth-order Runge-Kutta method. MATLAB m-files were developed and were used to solve the coupled machine model under transient condition. The thermal resistances and capacitances were determined and calculated with the help of purely dimensional information from the machine geometry and constant thermal coefficients and their values were accepted as inputs by the MATLAB m-files. The results show that the temperature rise for various parts of the machine with the rotor iron and bar having a peak temperature rise of $229^{\circ} \mathrm{C}$ at approximately $0.15 \mathrm{~s}$ during motor start-up.
\end{abstract}

Keywords: induction machine, electrical model, mechanical model, thermal model, coupling, improved thermal performance

\section{INTRODUCTION}

Rotating electrical machines, generally, converts electrical energy to mechanical energy or vice versa. This is made possible by the interaction of electrical circuits and magnetic fields across an air gap [1]. The interaction of the electrical and mechanical parts of electrical machines give rise to the heating of the machine's constituents parts, which consequently leads to an increase in temperature which if not properly monitored may lead to the breakdown of the machine.

Previous works on induction machine have explained how Electrical and Mechanical models of the machine can be developed [2 - 5]. Unfortunately, these works lack the ability to explore the thermal behavior of the machine as well as simultaneously predict the dynamic behavior of the machine due to Electrical and Mechanical transients [6].

Two-mass experimental system stand is designed to measure speed and torque responses of the first mass and to change the load. In the physical construction, an induction system consists of mechanical and electrical parts. Mechanical part consists of rotating elements. They are interconnected by the special chains which have elasticity and potential clearance. The electrical part consists of supply, brake and measuring devices. Induction motor with squirrelcage rotor is the first mass of system [7]. The second induction motor with the same parameters serves as the load of the first mass. The second mass characterizes rotor inertia of the second motor.

Thermal modeling is important for design purpose, fault detection and for the correct parameter estimation during motor operation. Thermal models based on finite difference method or finite element methods provides a detailed result for the conduction mode but the modeling of convection and radiation modes is difficult moreover it may be difficult to account for any change in machine design parameter. The finite element method is particularly sound for solving transient or steady-state problems with large temperature gradients within individual machine 
parts, like, high-inertia starts, unbalanced operation or thermal asymmetries caused by ventilation failure in large machines $[8,9]$. The main problem of the finite element method is that three dimensional and timedependent problems are challenging both in software development and hardware requirements [10].

A lumped parameter model is used in the thermal aspect of the machine model[11-13].The aim of the reduction of heat energy in induction machine is to develop an appropriate thermal model that can be used as a tool for constructing and monitoring of induction motors and to illustrate all associated problems and aspects of implementation. These types of models are based on dividing the machine into several elements. Each of which is identified as a node having a thermal capacitance, a heat source and then interconnected through thermal conductance forming an equivalent thermal network.

In the proposed coupled model, the electrical model generates the electromagnetic torque. This torque is fed into the mechanical model. The mechanical model produces the power losses which is needed by the thermal model in order to predict the machine temperatures. The machine temperatures so generated from the thermal model is fed back to the electrical model because the rotor and stator resistances are temperature dependent. The electrical model of the machine is first developed followed by the mechanical model. This continues with the thermal modeling as shown in figure 1. The Electrical model is expected to determine the losses dissipated in the various parts of the rotor. The stator and rotor equivalent resistances are varied as functions of their average temperatures. The thermal model is derived by considering the power losses and rate of temperature rise in various parts of the motor. The model thermal resistances and capacitances are evaluated using the motor construction data. The input to the thermal model is calculated from the electrical model. The mechanical model comprises of the equations of motion of the motor and driven load. By using the mechanical model, motor speed can be measured or calculated during motor operation. The mechanical model, therefore presents the motor speed as an input to the electrical model. Therefore, by coupling the electrical and thermal models, the power losses of the thermal model are given by the electrical model while the temperatures in the equivalent resistances used in the electrical model are corrected by the thermal model. The two models are calculated in parallel. It is imperative to state that before each calculation step of temperatures, the heat loss inputs have to be determined. The strategy for evaluating these losses for every need of the thermal model takes enormous computer time since the thermal time constants of the motor are higher than the electrical ones [14].

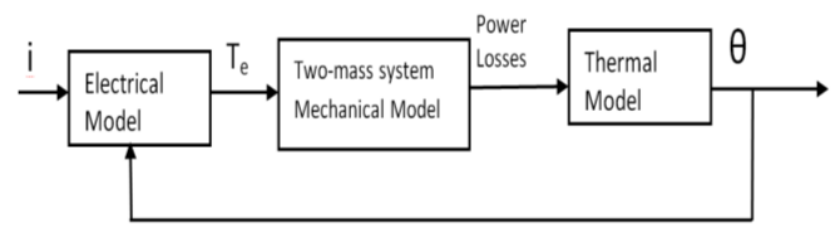

Figure 1: Block Diagram of the proposed coupled model

In this research work, a performance improvement of induction machine using the electrical-thermal coupling technique is carried out using a two-mass system as the mechanical model as against a one-mass system. Particular attention is given to the modelling of a two-mass system which leads to satisfactory coupling results. Two-mass drive system is designed to measure speed and torque responses of the first mass and to change the load. It is convenient in high power applications and for high system reliability

\section{PROPOSED ELECTRICAL-THERMAL MODELS}

\subsection{Electrical Model}

The differential equations which govern the transient performance of the induction motor can be described in a number of ways, but only differ in detail and in their suitability for use in a given application. Conventionally, machine model is developed using the method of reducing the machine to an axis-coil ( $d-q$ axis) model on both the stator and rotor. D-q axis model of the motor provides a convenient way of modeling the machine and it is the most suitable for numerical solution. The differential equations which best describe the dynamic performance of an ideal symmetrical induction machine in an arbitrary reference frame could be derived from the $\mathrm{d}-\mathrm{q}$ equivalent circuits. The electrical model of the squirrel-cage asynchronous machine in rotor reference frame as in [2] is given as:

$$
\left[\begin{array}{c}
V_{q s} \\
V_{d s} \\
0 \\
0
\end{array}\right]=\left[\begin{array}{cccc}
\left(R_{s}+L_{s} P\right) & -\omega_{r} L_{s} & L_{m} P & \omega_{r} L_{m} \\
-\omega_{r} L_{s} & \left(R_{s}+L_{s} P\right) & -\omega_{r} L_{m} & L_{m} P \\
L_{m} P & 0 & \left(R_{r}+L_{r} P\right) & 0 \\
0 & L_{m} P & 0 & \left(R_{r}+L_{r} P\right)
\end{array}\right]\left[\begin{array}{c}
i_{q s} \\
i_{d s} \\
i_{q r} \\
i_{d r}
\end{array}\right]
$$




$$
p[i]=-[L]^{-1}\left([R]+\omega_{r}[G]\right)[i]+[L]^{-1}[V]
$$
where,

$$
\begin{aligned}
& {[V]=\left[\begin{array}{lllll}
V_{q s} & V_{d s} & 0 & 0
\end{array}\right]^{t}} \\
& {[R]=\left[\begin{array}{cccc}
R_{S} & 0 & 0 & 0 \\
0 & R_{S} & 0 & 0 \\
0 & 0 & R_{r} & 0 \\
0 & 0 & 0 & R_{r}
\end{array}\right]} \\
& {[L]=\left[\begin{array}{cccc}
L_{s} & 0 & L_{m} & 0 \\
0 & L_{s} & 0 & L_{m} \\
L_{m} & 0 & L_{r} & 0 \\
0 & L_{m} & 0 & L_{r}
\end{array}\right]} \\
& {[G]=\left[\begin{array}{cccc}
0 & L_{s} & 0 & L_{m} \\
-L_{s} & 0 & -L_{m} & 0 \\
0 & 0 & 0 & 0 \\
0 & 0 & 0 & 0
\end{array}\right]} \\
& {[i]=\left[\begin{array}{llll}
i_{q s} & i_{d s} & i_{q r} & i_{d r}
\end{array}\right]^{t}}
\end{aligned}
$$

The electromagnetic torque is given by [15] as

$$
T_{e}=\frac{3}{2} P L_{m}\left(i_{q s} i_{d r}-i_{d s} i_{d r}\right)
$$

In (8), $\mathrm{P}$ is the Number of pole pairs. The stator voltages are balanced and represented as:

$$
\begin{gathered}
V_{a s}=\sqrt{2} \mathrm{~V} \cos \omega_{\mathrm{b}} \mathrm{t} \\
V_{b s}=\sqrt{2} \mathrm{~V} \cos \left(\omega_{\mathrm{b}} \mathrm{t}-\frac{2 \pi}{3}\right) \\
V_{c s}=\sqrt{2} \mathrm{~V} \cos \left(\omega_{\mathrm{b}} \mathrm{t}-\frac{2 \pi}{3}\right)
\end{gathered}
$$

These stator voltages are related to the $d-q$ frame of reference by equation below

$$
\left[\begin{array}{c}
V_{q s} \\
V_{d}
\end{array}\right]=\left[C_{1}\right]\left[\begin{array}{l}
V_{a s} \\
V_{b s} \\
V_{c s}
\end{array}\right]
$$

Where,

$$
C_{1}=\frac{2}{3}\left[\begin{array}{c}
\cos \theta, \cos \left(\theta_{r}-\frac{2 \pi}{3}\right) \cos \left(\theta_{r}-\frac{4 \pi}{3}\right) \\
\sin \theta, \sin \left(\theta_{r}-\frac{2 \pi}{3}\right) \sin \left(\theta_{r}-\frac{4 \pi}{3}\right)
\end{array}\right]
$$

\subsection{Mechanical Model}

In the proposed model, a two-mass system is considered due to the coupling of the induction machine to a load. Figure 2 shows a schematic of a two-mass system consisting of two lumped inertias $J_{M}$ and $\mathrm{J}_{\mathrm{L}}$, representing the motor and load, respectively, coupled via a shaft of finite stiffness $\mathrm{K}_{\mathrm{S}}$, that is subject to torsional torque $\mathrm{T}_{\mathrm{S}}$ and excited by a combination of electromagnetic torque $\mathrm{T}_{\mathrm{M}}$ and load-torque perturbations $\mathrm{T}_{\mathrm{L}}$. The motor angular velocity is denoted $\omega_{\mathrm{M}}$ and the load velocity is denoted $\omega_{\mathrm{L}}$ [16]. Two-mass system gives higher transient with a wide range of speed changers.

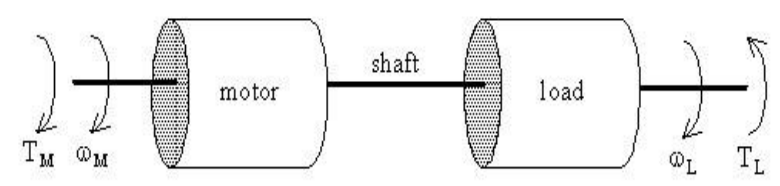

Figure 2: Two-mass drive system

The state equation of two-mass system is shown as (14) at the bottom of this page wherein $K_{s}$ is the haft stiffness, $B_{s}$ is the Shaft damping coefficient, $J_{M}$ is the Motor inertia, $\mathrm{B}_{\mathrm{M}}$ is the Coefficient of motor viscousity, $\mathrm{J}_{\mathrm{L}}$ is the Load inertia, $\mathrm{B}_{\mathrm{L}}$ is the Coefficient of load inertia

\subsection{Thermal Model}

In developing the thermal network model, the machine geometry is divided into basic elements and each element being identified by a node in the thermal network with its corresponding thermal capacitance and heat sources. This model consists of 4 nodes and 6 thermal resistances. In this model, the electromagnetic losses are given as input. The value of the thermal resistance and capacitance will be calculated with the help of heat transfer theory.

The developed thermal network model is shown in Figure 3. The stator iron and the Frame constitute a network. The stator winding forms a separate network. The rotor iron and the copper components in rotor are lumped into a network.

The high level of accuracy could be achieved by modest subdivision of the induction machine's geometrical parts [17].The system of algebraic and differential equations which describes the thermal behavior of the developed thermal network model under transient condition is shown in equations (1518). The transient thermal network equations of the thermal model, taken node by node gives (15) through (18).

$$
\begin{gathered}
\frac{d}{d t} \omega_{M}=\frac{-B_{M}}{J_{M}} \omega_{M}-\frac{1}{J_{M}} T_{S}+\frac{1}{J_{M}} T_{M} \\
\frac{d}{d t} T_{S}=\left(K_{S}-\frac{B_{M} B_{S}}{J_{M}}\right) \omega_{M}-\left(K_{S}-\frac{B_{L} B_{S}}{J_{L}}\right) \omega_{L}-B_{S}\left(-\frac{1}{J_{M}}+\frac{1}{J_{L}}\right) T_{S}+\frac{B_{S}}{J_{M}} T_{M}+\frac{B_{S}}{J_{L}} T_{L} \\
\frac{d}{d t} \omega_{L}=\frac{-B_{M}}{J_{L}} \omega_{L}-\frac{1}{J_{L}} T_{S}+\frac{1}{L} T_{L}
\end{gathered}
$$




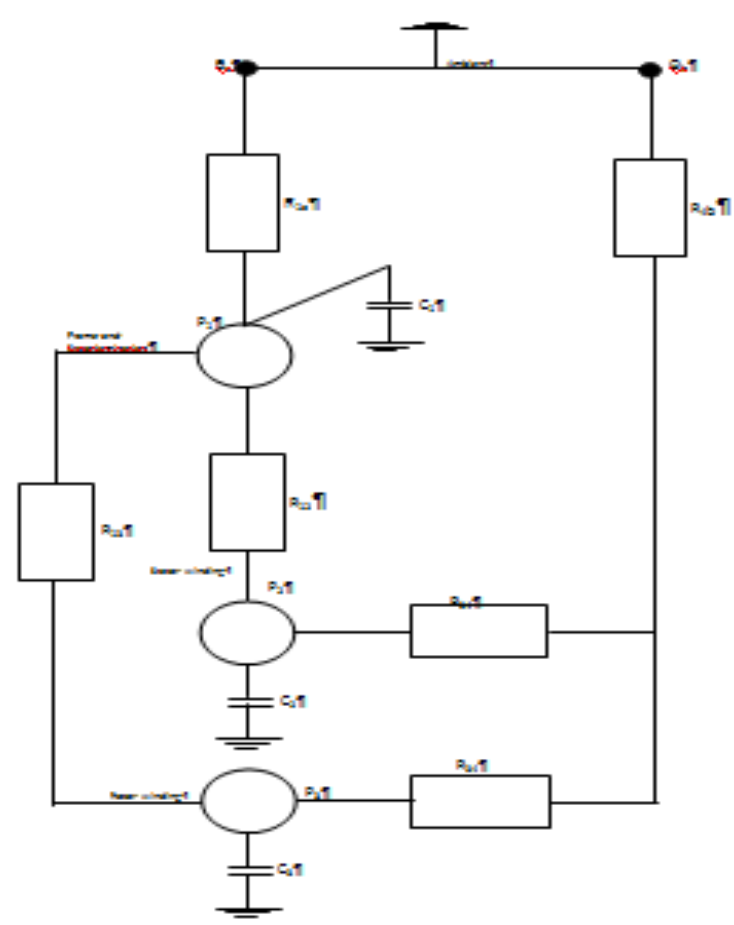

Figure 3: The proposed thermal network model

$$
\begin{aligned}
P_{1}=C_{1} \frac{d \theta_{1}}{d t}+ & \frac{1}{R_{1 a}}\left(\theta_{1}-\theta_{a}\right)+\frac{1}{R_{12}}\left(\theta_{1}-\theta_{2}\right) \\
& +\frac{1}{R_{13}}\left(\theta_{1}-\theta_{3}\right) \\
P_{2}=C_{2} \frac{d \theta_{2}}{d t}+ & \frac{1}{R_{21}}\left(\theta_{2}-\theta_{1}\right)+\frac{1}{R_{24}}\left(\theta_{2}-\theta_{4}\right) \\
P_{3}=C_{3} \frac{d \theta_{3}}{d t}+ & \frac{1}{R_{31}}\left(\theta_{3}-\theta_{1}\right)+\frac{1}{R_{34}}\left(\theta_{3}-\theta_{4}\right) \\
P_{4}=C_{4} \frac{d \theta_{4}}{d t}+ & \frac{1}{R_{4 a}}\left(\theta_{4}-\theta_{b}\right)+\frac{1}{R_{42}}\left(\theta_{4}-\theta_{2}\right) \\
& +\frac{1}{R_{43}}\left(\theta_{4}-\theta_{3}\right)
\end{aligned}
$$

In order for these equations to be suitable for computer simulation purposes, equations (15-18) will be re-arranged in state variable form shown in (19) shown below this page wherein, $\mathrm{P}_{1} \ldots \ldots \ldots . . \mathrm{P}_{4}$ is the heat losses in node 1 , node 2 , node 3 and node $4, \theta_{1} \ldots \ldots . . . \theta_{2}$ is the temperature rises at the different nodes, $\mathrm{R}_{1 \mathrm{a}}$
......... $\mathrm{R}_{43}$ is the thermal resistances, $\mathrm{C}_{1}$ $\ldots . \mathrm{C}_{4}$ is the thermal capacitances at the different nodes.

$$
\mathrm{G}_{1 \mathrm{a}}=\frac{1}{R_{1 a}}, \mathrm{G}_{12}=\frac{1}{R_{12}}, \mathrm{G}_{24} \frac{1}{R_{24}}
$$

etc.

\section{SIMULATION AND DISCUSSION OF RESULT}

In order to predict the dynamic performances of the machine, the model equations in state variable form together with the currents in state variables are used. MATLAB function program which describes the differential equations of the machine in dynamic condition is developed. The developed program accepts constant stator and rotor quantities - such as resistance and capacitance as inputs. The values of the thermal resistances and capacitances were calculated according to the principles reported by [5]. Table 1 shows the computed values.

Table 1: Calculated thermal resistances and capacitances.

\begin{tabular}{llll}
\hline $\begin{array}{c}\text { Thermal } \\
\text { Capacitance }\end{array}$ & Values $[\mathrm{J} / \mathrm{K}]$ & $\begin{array}{c}\text { Thermal } \\
\text { Resistance }\end{array}$ & $\begin{array}{c}\text { Values } \\
{[\mathrm{K} / \mathrm{W}]}\end{array}$ \\
\hline $\mathrm{C}_{1}$ & 11890.66 & $\mathrm{R}_{1 \mathrm{a}}$ & 0.0416 \\
$\mathrm{C}_{2}$ & 3487.69 & $\mathrm{R}_{12}$ & 0.06238 \\
$\mathrm{C}_{3}$ & 179.358 & $\mathrm{R}_{13}$ & 0.150 \\
$\mathrm{C}_{4}$ & 902.38 & $\mathrm{R}_{24}$ & 0.1476 \\
& & $\mathrm{R}_{34}$ & 0.041 \\
& & $\mathrm{R}_{4 \mathrm{~b}}$ & 0.015 \\
\hline
\end{tabular}

The MATLAB m-file in [19] uses Runge-Kutta numerical method to solve the state variable representation of the dynamic nature of the machine. The mechanical model of the machine is also developed. The transient behaviour of the induction machine at run-up can now be simulated.

The developed thermal model gives rise to a set of algebraic and differential equations which describes the thermal behaviour of the machine under transient condition. MATLAB m-files are also developed to solve for the thermal model for half of the machine in order to determine the average temperature rise in the various parts of the machine.

$$
\begin{aligned}
& {\left[\begin{array}{l}
\theta_{1} \\
\theta_{2} \\
\theta_{3} \\
\theta_{4}
\end{array}\right]=\left[\begin{array}{cccc}
C_{1} & 0 & 0 & 0 \\
0 & C_{2} & 0 & 0 \\
0 & 0 & C_{3} & 0 \\
0 & 0 & 0 & C_{4}
\end{array}\right]^{-1}\left[\begin{array}{c}
P_{1}+G_{1 a} * \theta_{a} \\
P_{2} \\
P_{2} \\
P_{4}+G_{4 b} * \theta_{b}
\end{array}\right]-\left[\begin{array}{cccc}
C_{1} & 0 & 0 & 0 \\
0 & C_{2} & 0 & 0 \\
0 & 0 & C_{3} & 0 \\
0 & 0 & 0 & C_{4}
\end{array}\right]^{-1}} \\
& \times\left[\begin{array}{c}
\left(G_{1 a}+G_{12}+G_{13}\right) \\
-G_{21} \\
-G_{31} \\
0-G_{42}
\end{array}\right. \\
& \left.\begin{array}{ccc}
-G_{12} & -G_{13} & 0 \\
\left(G_{21}+G_{24}\right) & 0 & -G_{24} \\
0 & \left.-G_{31}+G_{34}\right) & -G_{34} \\
-G_{43} & \multicolumn{2}{c}{\left(G_{4 b}+G_{42}+G_{43}\right)}
\end{array}\right]\left[\begin{array}{l}
\theta_{1} \\
\theta_{2} \\
\theta_{3} \\
\theta_{4}
\end{array}\right]
\end{aligned}
$$


The time function of the speed, electromagnetic torque, stator phase currents and resistances are shown in Figure 4, Figure 5 and Figure 6. Figure 7 shows the heat losses associated with the component parts of the test machine. The graph of rotor speed as against time in Figure 5 shows that the speed of the machine drops at time equals $0.2 \mathrm{~s}$ due to the applications of load. But at the instant of the load application, the torque increases from $0 \mathrm{Nm}$ to $31 \mathrm{Nm}$ which is the value of the mechanical load torque as the electromagnetic-time curve depicts. Figure 5 shows that the transient period of the machine. Figure 6
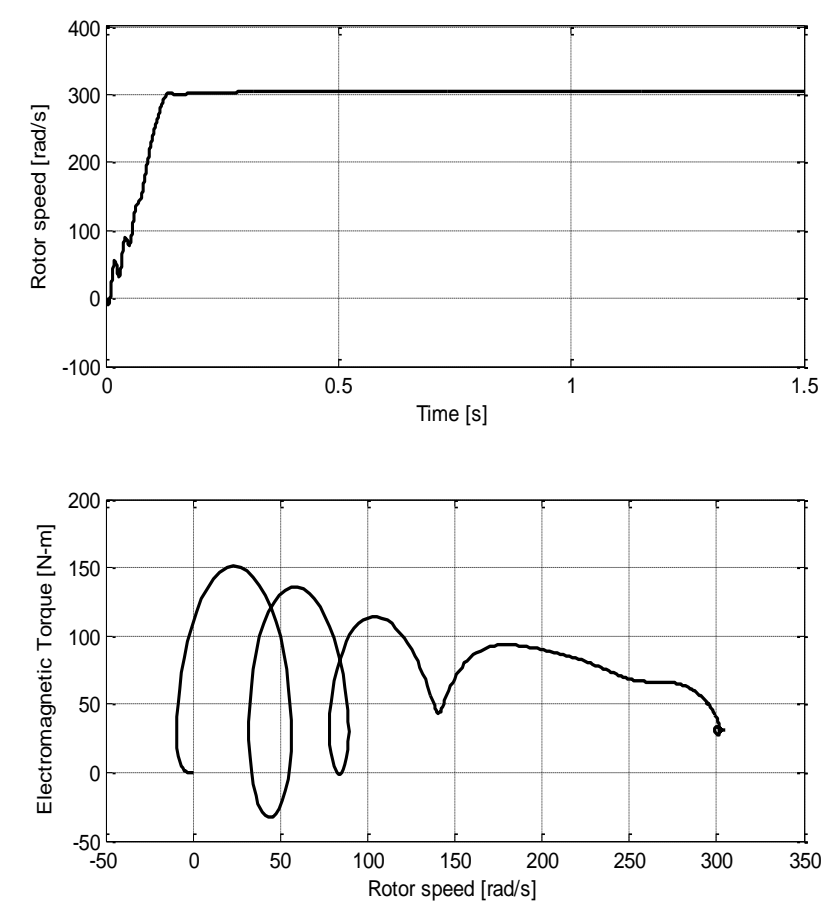

Figure 4: Predicted time function of Speed and Torque at run-up conditions

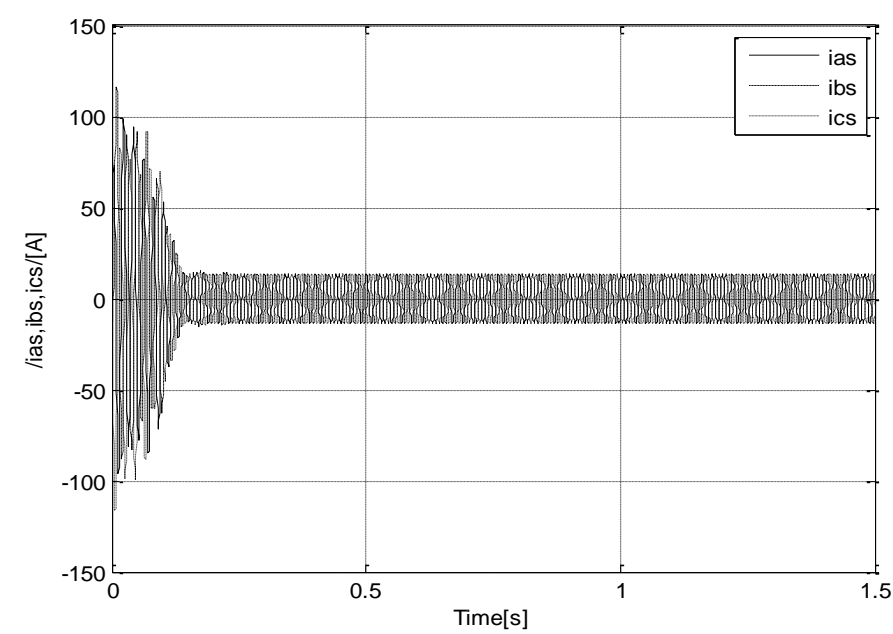

Figure 5: predicted time function of stator phase currents at run-up condition shows that both the stator and rotor resistances have an initial peak rise but remain constant after the application of load. Figure 7 shows that great amount of heat losses occur at the rotor iron and rotor bar and the stator winding of the test machine. The stator winding have the least heat losses. Figure 8 shows the temperature rise of the various parts of the machine when coupled. The rotor iron and rotor bar respond sharply to heat compared to other parts of the machine with a peak temperature of about $229^{\circ} \mathrm{C}$. The various parts are shown in Table 2
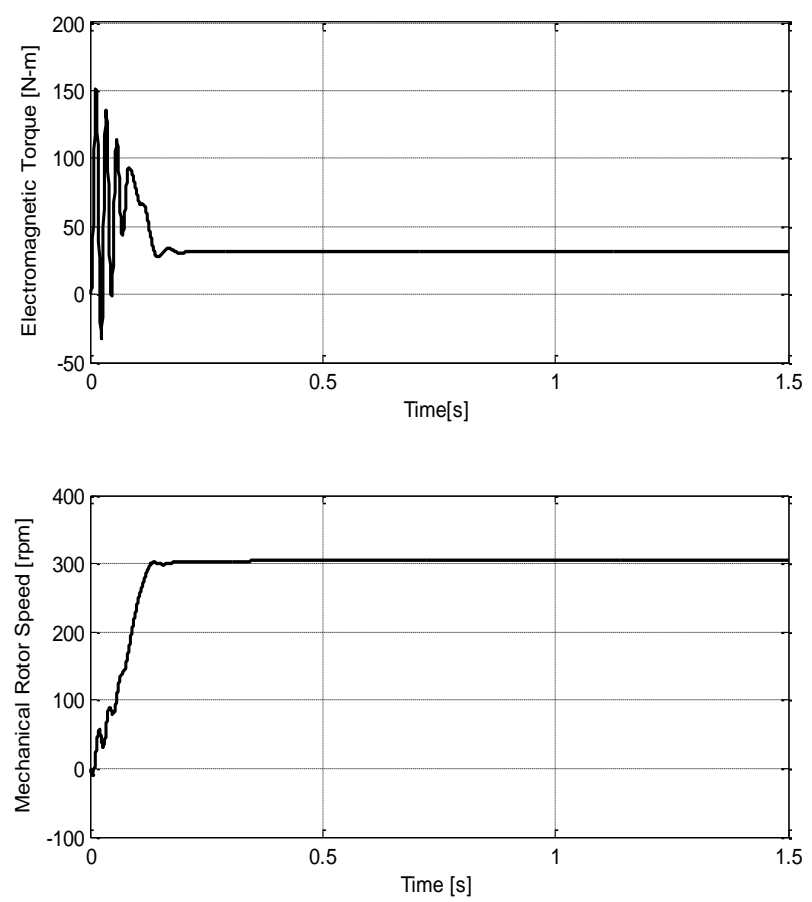
predicted steady state temperature rises for the

Figure 6: Predicted time function of stator and rotor resistances 


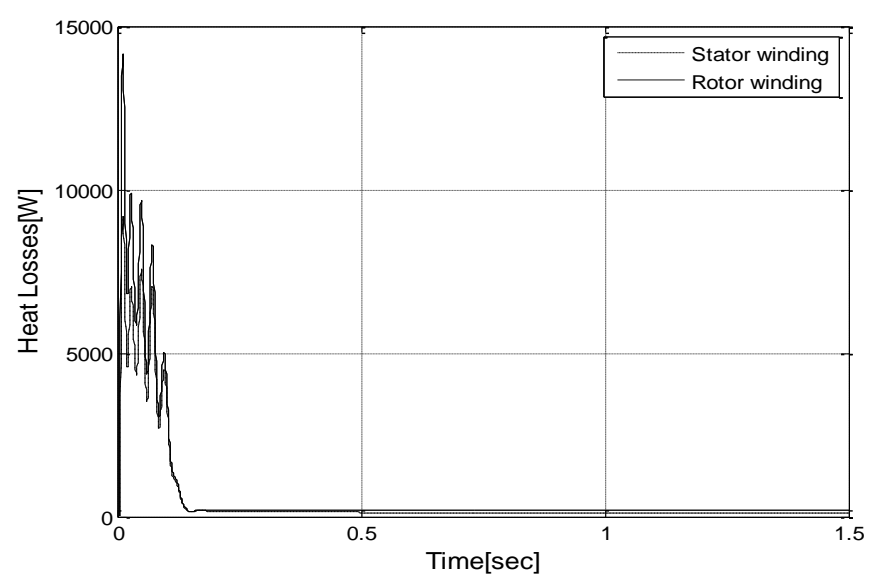

Figure 7: Predicted time function of heat losses in stator winding and rotor winding

Table 2: Steady-State temperatures with coupling

\begin{tabular}{lc}
\hline \multicolumn{1}{c}{ Model Component } & Temperature $\left({ }^{\circ} \mathrm{C}\right)$ \\
\hline Stator Iron and Frame & 46.70 \\
Stator Winding & 48.32 \\
Rotor iron and Rotor Bar & 42.84 \\
End-winding & 34.47 \\
\hline
\end{tabular}

\section{CONCLUSION AND OBSERVATION}

The main aim of this paper was to develop models that accurately represent the Electrical-Thermal coupling of induction machine which helps in its performance improvement. The overall behaviour of the induction machine in terms of the thermal, electrical and mechanical transient behaviours can be predicted. This is in contrast to the conventional model which cannot be used to monitor the average temperatures of the different parts of the machine. In figure 9, the stator iron and frame, stator winding, rotor iron and bar and the end winding average temperatures rise very sharply within a short time interval.

A d-q axis model has been used to predict the electrical characteristics of the machine with temperature effect and heat losses incorporated. A two-mass system was used to model the mechanical characteristics of the machine. A great amount of heat is dissipated in the stator winding of the squirrel-cage induction machine in Figure 7. With the result of the analysis from the models, currents, temperatures, torque and speed can be monitored and controlled simultaneously.

The proposed thermal model is based on thermal networks which are very effective in the thermal modelling of electrical machines. Machines constructions can be easily modelled and the calculation does not require high capacity computers. The input for the thermal-network MATLAB program is the geometry, material constraints and the

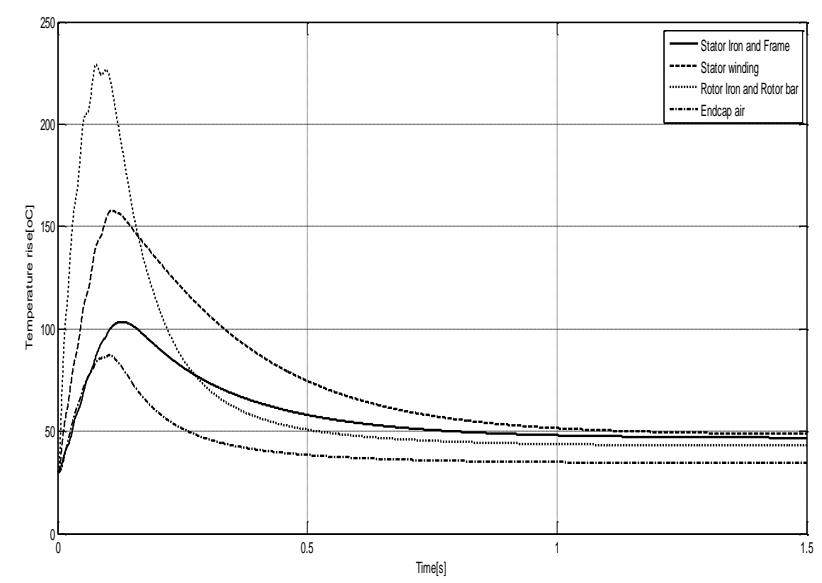

Figure 8: Predicted Temperatures of the coupled model

electromagnetic heat losses of the machine. The program gives the temperature distribution of the machine as an output. Due to symmetry of the motor, half of the machine was simulated.

An important goal was to establish methods to identify unknown thermal resistances, since there does not seem to exist any recommendations on how such measurements should be performed. It would of course be best to make a direct measurement of the unknown thermal resistances, but unfortunately this would necessitate the making of complicated dummies. This goal has instead been achieved by the use of identification models which are developed and the parameters can be determined from dimensional information, thermal properties of the materials used and the constant heat transfer co-efficient. Therefore, the proposed coupled model is capable of calculating the temperatures in the machine with good accuracy during steady and transient conditions.

\section{REFERENCES}

[1] Cochran, P. L. "Polyphase induction motors: Design, and Application" Marcel Dekker, Inc, NewYork/USA, (1989).

[2] Krause P.C and Thomas C.H: "Simulation of symmetrical induction machinery" Transactions IEEE, vol. PAS-84 No. 11, , pp. 1038-1053. (1965).

[3] Smith, J. R. and Sriharan, S. "Transient performance of the induction motor" Proc. IEE, 113, (7), , Pp 1173-1181. (1966).

[4] Driesen J. Belmans, R. and Hameyar, K. "Coupled magneto-thermal simulation of thermally anisotropic electrical machines", in Proc. IEEE IEMD, Seattle WA, May, pp. 469-471. (1999).

[5] Mezani, S. Takorabet, N. and Laporte, B. "A combined electromagnetic and thermal analysis of 
induction motors", IEEE Transactions on Magnetics, vol. 41, no. 5, pp. 1572-1575, May (2005).

[6] Okoro, O. I., "Analysis of Electrical-Thermal coupling of induction machine". Global journal of Engineering Research, Vol. 1 \& 2, Pp. 21-37, (2004).

[7] Juraitis, S; Rinkeviciene, R; Kilikevicius, A. "Experimental investigation of Two-mass Electromechanical system" Elektronika IR elektrotechika vol 18, no. 10 (2012).

[8] Ibtiouen, R. Mezani, S. Touhami, O. nouali, N. and Benhaddadi, M, "Application of lumped parameters and finite element methods to the thermal modelling of an induction motor" IEEE Conference Publication on Electric Machines and Drives, February 2001, pp. 505-507

[9] Rajagopal, M. S. Seetharamu, K. N. and Ashwathnarayana, P. A. "Transient thermal analysis of induction motors", IEEE Transactions on Energy Conversion, vol. 13, no. 1, pp. 62-69, March (1998).

[10] Bastos, J. P. Cabreira, M. F. R. R. Sadowski, N. Arruda, S. R. and Nau, S. L. "A Thermal Analysis of Induction Motors Using a Weak Coupled Modeling", IEEE Transactions on Magnetics, vol. 33, no. 2, pp. 1714-1717, March (1997).

[11] Boglietti, A., Cavagnino, A., and Staton, D., "Determination of critical parameters in electrical machine thermal models", IEEE Transactions on Industry Applications, vol. 44, no. 4, July/August 2008, pp. 1150-(1159).
[12] Kral, C. Haumer, A. and Bauml, T. "Thermal model and behavior of a totally-enclosed-water-cooled squirrel-cage induction machine for traction applications," IEEE Trans. Ind. Electron., vol. 55, no. 10, pp. 3555-3565, Oct. (2008).

[13] Boglietti, A., Cavagnino, A., Lazzari, M., and Pastorelli, M., "A simplified thermal model for variable-speed self-cooled industrial induction motor," IEEE Trans. Ind. Appl., vol. 39, no. 4, pp. 945-952, Jul./Aug. 2003.

[14] Hachida, M. R; Ghariani, M and Neji, R, "Thermal model for induction machine" IEEE SSD, Sousse, pp. 22-25 2011, March (2011).

[15] Krause, P. C., Analysis of Electric Machinery, New York, McGraw-Hill, (1986).

[16] Ocal, 0; Soylemez, M. T and Bir, A "Robust pole assignment using coefficient diagram method" International Conference on Automatic Control and Systems Engineering (ACSE) Cairo, Egypt, December, 2005, pp.197-202.

[17] Kylander, G. "Thermal modelling of small cage induction motors" Doctor of Technology Thesis, Chalmers University of Technology, Gothernburg, Sweden, (1995).

[18] Okoro, O. I. "Dynamic and thermal modelling of induction machine with Non-linear Effects" Dissertation, Universität Kassel/Germany, (2002).

[19] The MATLAB User's guide, The MathworksInc, Natick, (1991). 